\title{
PENGARUH METODE ECONOMIC VALUE ADDED (EVA), RETURN ON ASSET (ROA), RETURN ON EQUITY (ROE), DAN DEBT TO EQUITY RATIO (DER) TERHADAP RETURN SAHAM
}

\author{
Monica Faulina Fernandus \\ Program Studi Magister Manajemen Universitas Tarumanagara \\ monica.faulina@gmail.com \\ Indra Widjaja \\ Program Studi Magister Manajemen Universitas Tarumanagara \\ Masuk : 06-12-2019, revisi : 21-12-2019 diterima untuk diterbitkan : 21-12-2019
}

\begin{abstract}
Performance measurement can be used to measure company's success in a certain period of time and can be used as input for improvement of the company in the future. In measuring company performance, investors usually see financial performance reflected in various ratios. Managerial work measurements rarely use value added calculation approach to the cost of invested capital. Because of the limitations and weaknesses of the ratio, EVA method emerged as a measure of company performance.

This study aims to determine whether LQ45 companies in Indonesia have succeeded in adding value, so their performance is positive and which is the most significant performance evaluation methods: EVA, ROA, ROE, or DER. The research period is within 2016-2018 using Eviews 9.

The results showed that although the companies are listed in the LQ45 category, the use of capital structure policies are not optimal and random effect method states DER as the most significant method for measuring company performance.
\end{abstract}

Abstrak : Pengukuran kinerja dapat digunakan untuk mengukur kesuksesan perusahaan dalam periode waktu tertentu dan sebagai masukan untuk pengembangan perusahaan di masa depan. Dalam mengukur kinerja perusahaan, investor biasanya melihat kinerja keuangan dalam berbagai rasio. Pengukuran kerja manajerial jarang menggunakan pendekatan perhitungan nilai tambah untuk biaya modal yang diinvestasikan. Karena keterbatasan dan kelemahan rasio, metode EVA muncul sebagai ukuran kinerja perusahaan.

Penelitian ini bertujuan untuk mengetahui apakah perusahaan LQ45 di Indonesia telah berhasil menambah nilai, sehingga kinerjanya positif dan manakah metode untuk menilai kinerja yang paling signifikan: EVA, ROA, ROE, atau DER. Periode penelitian tahun 2016 2018 menggunakan Eviews 9.

Hasil penelitian menunjukkan bahwa meski perusahaan terdaftar dalam kategori LQ45, penggunaan kebijakan struktur modalnya tidak optimal dan metode efek random menyatakan bahwa $D E R$ sebagai metode yang paling signifikan untuk mengukur kinerja perusahaan.

Keywords : Economic Value Added (EVA), Return on Asset (ROA), Return on Equity (ROE), Debt to Equity Ratio (DER), Return Saham

\section{PENDAHULUAN}

Dalam mengukur kinerja perusahaan, investor biasanya melihat kinerja keuangan yang tercermin dari berbagai macam rasio. Namun ada keterbatasan dan kelemahan analisis rasio, yakni : 
1. Tidak memperhitungkan biaya modal sehingga dapat menghasilkan keputusan yang misleading karena hanya memfokuskan pada investasi dengan tingkat pengembalian tinggi tanpa memperhatikan tingkat resiko investasi.

2. Belum dapat mengatasi konflik yang muncul. Manajemen berkepentingan memaksimumkan tingkat pengembalian yang akan memperbaiki kinerja perusahaannya, sedangkan investor berkepentingan untuk meminimumkan tingkat resiko investasinya.

3. Tidak dapat berdiri sendiri karena memerlukan data pembanding seperti standar industri dan sering kali tidak tersedia.

Atas kelemahan ini maka muncul metode EVA (Economic Value Added) sebagai ukuran kinerja perusahaan. Tujuan dari penelitian ini adalah :

1. Untuk mengetahui kinerja perusahaan yang termasuk dalam indeks LQ45 menggunakan metode $E V A$, apakah sudah mengunakan biaya modal yang efisien atau belum.

2. Untuk mengetahui pengaruh $E V A, R O A, R O E, D E R$ terhadap return saham perusahaan.

3. Untuk mengetahui metode manakah dari 4 metode tersebut yang paling berpengaruh terhadap return saham perusahaan.

\section{TINJAUAN PUSTAKA}

\section{Penelitian Terdahulu}

Terdapat beberapa penelitian terdahulu mengenai pengaruh EVA Terhadap Return Saham yakni:

a. Value-based management, EVA and stock price performance in Canada

Menunjukkan perusahaan yang menggunakan EVA punya harga saham yang lebih baik.

b. EVA \& MVA as performance measures and signals for strategic change

Dibandingkan dengan pengukuran lainnya EVA berkorelasi paling kuat dengan tingkat pengembalian saham.

c. EVA versus traditional accounting measures of performance as drivers of shareholder value - A comparative analysis

Indikator kinerja yang berkorelasi paling besar adalah MVA (38\%).

d. Value Creation of EVA and Traditional Accounting Measures: Indian Evidence

Penelitian yang dilakukan oleh Ekta Sikarwar Vijay Kumar Gupta (2016) hasilnya adalah EVA mengukur kinerja yang lebih baik daripada metode tradisional.

e. Valuation through EVA and Traditional Measures an Empirical Study

Dari analisis ditemukan bahwa $E V A$ adalah metode pengukuran terbaik yang tepat untuk mengukur nilai pemegang saham.

f. Does EVA® beat earnings? Evidence on associations with stock returns and firm values Menurut penelitian Gary C. Biddle, Robert M. Bowen, dan James S. Wallace (1996) bahwa metode rasio lebih berpengaruh signifikan dibandingkan dengan metode $E V A$.

\section{Rasio Analisis}

Metode yang umumnya digunakan untuk mengukur kinerja perusahaan adalah metode rasio keuangan. Berdasarkan tujuannya, rasio keuangan dibagi menjadi empat yaitu :

\section{a. Rasio Profitabilitas}

Rasio profitabilitas menunjukan kemampuan perusahaan menghasilkan keuntungan (laba). Terdapat lima ukuran yakni: Gross Profit Margin, Operating Profit Margin, Net Profit Margin, Return On Assets (ROA), dan Return On Equity (ROE).

b. Rasio Likuiditas

Rasio likuiditas menunjukan kemampuan perusahaan dalam memenuhi kewajiban finansial jangka pendeknya. Rasio yang sering digunakan untuk menghitung rasio ini yaitu Current Ratio dan Quick Ratio. 
c. Rasio Solvabilitas

Rasio solvabilitas menunjukkan kemampuan perusahaan untuk memenuhi semua kewajibannya, baik jangka panjang maupun jangka pendek jika perusahaan dilikuidasi. Terdapat 2 rasio yang digunakan untuk menghitung rasio ini yakni : Total Debt to Total Assets Ratio dan Debt to Equity Ratio (DER).

d. Rasio Aktivitas

Rasio Aktivitas digunakan untuk mengukur tingkat penggunaan aktiva atau kekayaan perusahaan sehingga akan diketahui aktiva mana yang produktif dan aktiva mana yang kurang produktif. Terdapat beberapa rasio aktivitas yakni: Rasio Perputaran Piutang, Rasio Perputaran Aktiva Tetap, Rasio Perputaran Persediaan, dan Rasio Perputaran Total Aktiva.

\section{Economic Value Added (EVA) dan Nilai Perusahaan}

Economic Value Added (EVA) merupakan indikator tentang adanya perubahan nilai dari suatu investasi. Menurut Steward dalam Young (1996) dinyatakan dengan rumus sebagai berikut :

Dimana :

$$
E V A=N O P A T-(\text { WACC } \mathrm{x} \text { Capital })
$$

NOPAT $=$ Laba operasi setelah pajak $; W A C C=$ Biaya modal rata-rata tertimbang ;

Invested Capital $=$ Jumlah modal yang diinvestasikan

Tolak ukur EVA dengan nilai perusahaan sebagai berikut :

a. Jika $E V A>0$, maka terjadi proses nilai tambah perusahaan.

b. Jika $E V A=0$, menunjukkan posisi impas perusahaan.

c. Jika $E V A<0$, berarti total biaya modal perusahaan lebih besar dari pada laba operasi setelah pajak yang diperolehnnya.

\section{Return Saham}

Return saham menurut Samsul (2006: 291) adalah pendapatan yang dinyatakan dalam persentase dari modal awal investasi. Pendapatan investasi dalam saham ini merupakan keuntungan yang diperoleh dari jual beli saham.

\section{METODOLOGI}

\section{Variabel Penelitian dan Operasionalisasi Variabel}

Berdasarkan perumusan masalah yang akan diteliti maka variabel yang akan diteliti adalah sebagai berikut:

1. Economic Value Added (EVA) sebagai $\mathrm{X}_{1}$ 4. Return on Equity (ROE) sebagai $\mathrm{X}_{3}$

2. Return on Assets (ROA) sebagai $\mathrm{X}_{2} \quad$ 5. Debt to Equity Ratio (DER) sebagai $\mathrm{X}_{4}$

3. Return on Equity (ROE) sebagai $\mathrm{X}_{3} \quad$ 6. Return saham sebagai $\mathrm{Y}$

.Tabel 1

Operasionalisasi Variabel

\begin{tabular}{|c|l|c|}
\hline No. & \multicolumn{1}{|c|}{ Variabel } & Pengukuran \\
\hline 1 & Economic Value Added $(E V A)$ & EVA $=$ NOPAT $-($ WACC $\times$ Capital $)$ \\
\hline 2 & Return on Assets $($ ROA $)$ & $R O A=\frac{\text { Laba bersih setelah pajak }}{\text { Total Aset }} \times 100 \%$ \\
\hline 3 & Return on Equity $(R O E)$ & $R O E=\frac{\text { Laba bersih setelah pajak }}{\text { Total Ekuitas }} \times 100 \%$ \\
\hline 4 & Return saham & Return Saham $=\frac{P 1-P 0}{P 0}$ \\
\hline
\end{tabular}




\section{Populasi, Sampel, Uji yang Digunakan}

Data yang digunakan untuk analisis adalah data perusahaan yang termasuk dalam LQ45 secara berturut-turut dalam rentang waktu 2016-2018 dan data keuangan lengkap. Setelah nilai $E V A, R O A, R O E, D E R$, dan return saham dihitung maka dilakukan uji regresi linier berganda data panel menggunakan software Eviews 9.

Perhitungan Economic Value Added (EVA)

Tabel 2

Economic Value Added (EVA)

\begin{tabular}{|c|c|c|c|}
\hline \multirow{2}{*}{$\begin{array}{c}\text { Kode } \\
\text { Perusahaan }\end{array}$} & \multicolumn{3}{|c|}{$E \boldsymbol{V A}$} \\
\hline & 2016 & 2017 & 2018 \\
\hline ADHI & - 219.614.877.031 & -100.144 .568 .889 & -118.285 .169 .530 \\
\hline ADRO & -3.080 & 23.009 & 7.661 \\
\hline ANTM & 7.914 .042 & -43.830 .024 & -393.644 .905 \\
\hline BBCA & -54.426 .008 & -21.643 .290 & -24.250 .628 \\
\hline BBNI & -13.288 .911 & -13.551 .642 & -12.814 .144 \\
\hline BBRI & -25.199 .010 & -31.787 .765 & -15.647 .935 \\
\hline BBTN & -10.489 .736 & -10.405 .475 & -10.128 .379 \\
\hline BMRI & -15.649 .310 & -21.024 .240 & -18.418 .604 \\
\hline BSDE & -563.659 .376 .680 & 20.724 .262 .892 & -883.880 .089 .545 \\
\hline GGRM & -5.515 .135 & -2.303 .474 & -1.716 .422 \\
\hline HMSP & 1.627 .168 & 9.079 .430 & 1.968 .513 \\
\hline ICBP & 548.575 & 557.416 & 641.695 \\
\hline INDF & -458.435 & -319.999 & -1.153 .675 \\
\hline INTP & 231.573 & 171.754 & 68.494 \\
\hline JSMR & -714.245 .933 & -288.586 .363 & -684.498 .626 \\
\hline KLBF & 245.112 .781 .978 & 197.639 .040 .241 & 215.618 .057 .978 \\
\hline LPKR & -42.886 & 120.240 & -426.146 \\
\hline LPPF & 990.250 & 869.513 & 530.601 \\
\hline MNCN & -370.003 & -59.038 & -164.167 \\
\hline PTBA & 333.436 & 796.665 & 881.771 \\
\hline PTPP & -23.542 .504 .550 & -422.494 .646 .483 & -384.534 .690 .185 \\
\hline SCMA & 159.368 .032 & 139.566 .504 & 184.781 .697 \\
\hline SRIL & -41.672 .237 & -56.073 .235 & -47.314 .661 \\
\hline SSMS & -52.503 .977 & -181.195 .044 & -123.656 .168 \\
\hline UNTR & -1.383 .333 & 361.928 & 1.380 .767 \\
\hline UNVR & 4.148 .836 & 4.275 .060 & 4.680 .958 \\
\hline WIKA & -333.110 .600 & -388.756 .209 & -376.002 .724 \\
\hline WSKT & -257.925 .552 .172 & -2.446 .619 .153 .261 & - 2.308.287.643.938 \\
\hline
\end{tabular}

\section{HASIL ANALISIS}

Berdasarkan analisis menggunakan software Eviews 9, diperoleh hasil bahwa metode Random Effect (MER) yang paling tepat untuk digunakan. Hasil analisis sebagai berikut : 


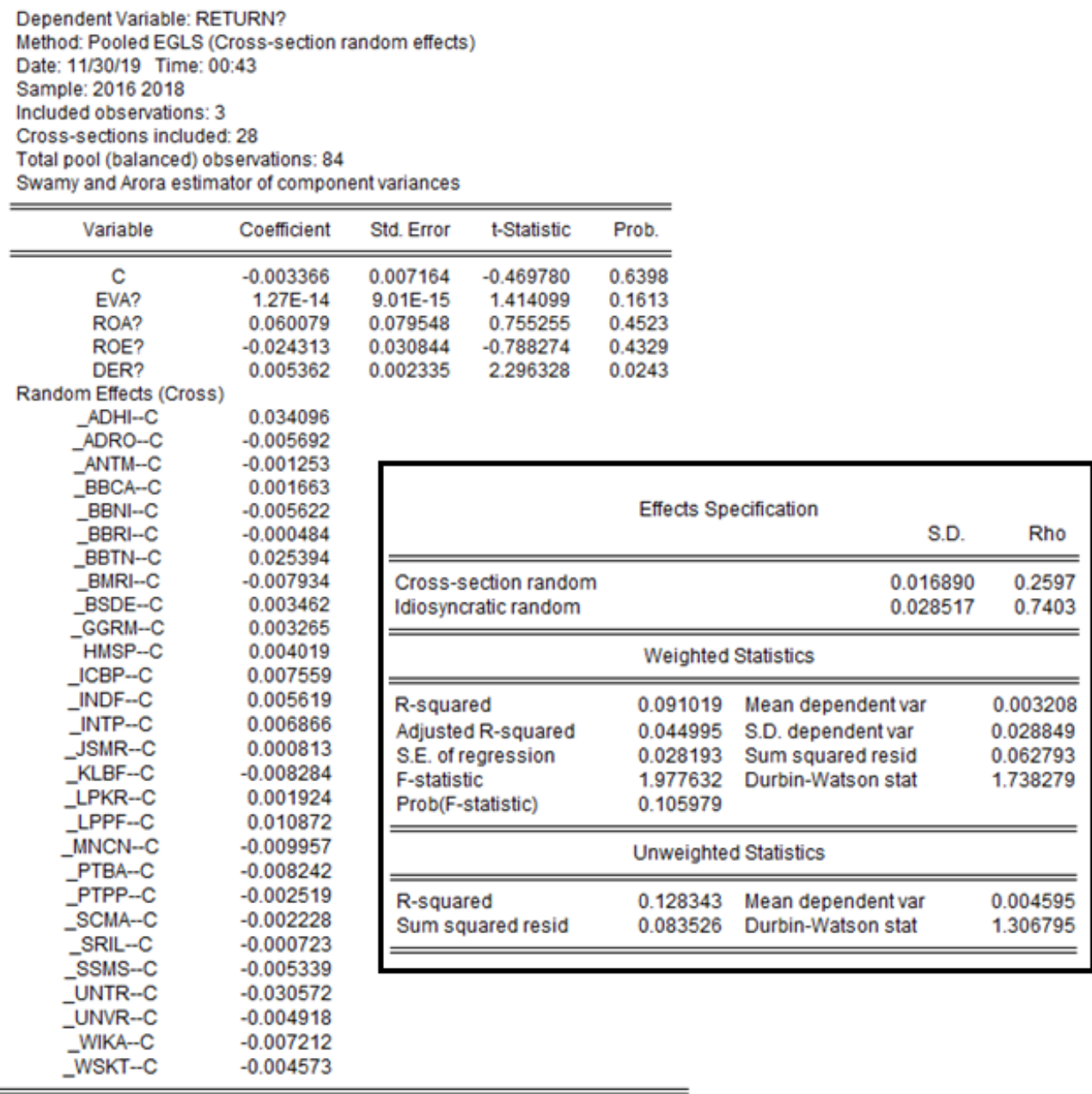

\section{Gambar 1 \\ Hasil Analisis MER}

\section{KESIMPULAN}

Berdasarkan pengujian yang dilakukan maka dipilih Metode Random Effect (MER) untuk analisis ini, dan kesimpulan penelitian sebagai berikut :

1. Perusahaan menghasilkan nilai EVA negatif yang menandakan biaya modal yang dikeluarkan lebih tinggi dari tingkat pengembalian yang dihasilkan. Keadaan ini mengambarkan bahwa kenyataannya walaupun perusahaan termasuk dalam kategori LQ45 namun belum mengunakan biaya modal yang efisien atau kebijakan pengunaan struktur modalnya belum optimal.

2. Pengaruh metode EVA, ROA, ROE, DER terhadap return saham :

a. EVA tidak berpengaruh signifikan dengan arah hubungan positif terhadap return saham yang mencerminkan kinerja perusahaan.

b. ROA tidak berpengaruh signifikan dengan arah hubungan positif terhadap return saham yang mencerminkan kinerja perusahaan.

c. $R O E$ tidak berpengaruh signifikan dengan arah hubungan negatif terhadap return saham yang mencerminkan kinerja perusahaan.

d. DER berpengaruh signifikan dengan arah hubungan positif terhadap return saham yang mencerminkan kinerja perusahaan.

3. Nilai Debt to Equity Ratio (DER) dapat digunakan sebagai salah satu metode penilaian kinerja perusahaan dibandingkan dengan metode lainnya (EVA, ROA, dan $\mathrm{ROE})$. 
DAFTAR PUSTAKA

Athanassakos, George. (2007). Value-based management, EVA and stock price performance in Canada. Management Decision, 45 (9), 1396-1411.

Biddle, Gary C., Bowen, Robert M., \& Wallace, James S. (1997). Does EVAt beat earnings? Evidence on associations with stock returns and firm values. Journal of Accounting and Economics, 24, 301-336.

Ferguson, Robert, Rentzler, Joel and Yu, Suasana. (2005). Does Economic Value Added (EVA) Improve Stock Performance Profitability?. Journal of Applied Finance, 101-113.

Gujarati dan Porter. (2009). Dasar-Dasar Ekonometrika. Jakarta : Salemba Empat.

Gupta, Ekta Sikarwar Vijay Kumar. (2016). Value creation of EVA and traditional accounting measures: Indian evidence. International Journal of Productivity and Performance Management, 65 (4), 1-14.

Helfert, Erich A. 1991. Techniques of Financial Analysis Seventh Edition. Boston : IRWIN.

Ismail, Ahmad. (2006). Is economic value added more associated with stock return than accounting earnings? The UK evidence. International Journal of Managerial Finance, 2 (4), 343-353.

Jakub, Salaga, Viera, Bartosova and Eva, Kicova. (2015). Economic Value Added as a measurement tool of financial performance. Procedia Economics and Finance, 26, 484489.

Lehn, Kenneth and Makhija, Anil K. (2017). EVA \& MVA as performance measures and signals for strategic change. Strategy \& Leadership, 24 (3), 34-38.

Nachrowi, D and Usman, Hardius. (2006). Pendekatan Populer dan Praktis Ekonometrika : Untuk Analisis Ekonomi dan Keuangan. Jakarta : Lembaga Penerbit Fakultas Universitas Indonesia.

Reddy, Dr. N R V Ramana, Rajesh, M. and Reddy, Dr. T. Narayana. (2011). Valuation through EVA and Traditional Measures an Empirical Study. International Journal of Trade, Economics and Finance, 2 (1), 19-23.

Riska, Sukarmanto, Edi., \& Nurhayati. (2014-2015). Pengaruh Economic Value Added (EVA) dan Rasio Profabilitas Terhadap Harga Saham : Studi Kasus Pada Perusahaan Pertambangan Yang Terdaftar Di Bursa Efek Indonesia (Periode 2010-2013). Prosiding Penelitian Sivitas Akademika Unisba (Sosial dan Humaniora), 2, 1-7.

Saidi. (2010). Analisis Kinerja Dengan Metode Economic Value Added : Studi Kasus PT. Astra International Tbk. Riset Manajemen dan Akuntansi, 1 (2), 50-67.

Sasongko, Noer and Wulandari, Nila. (2006). Pengaruh EVA Dan Rasio-Rasio Profitabilitas Terhadap Harga Saham. Empirika, 19 (1), 64-80.

Wet, JHvH de. (2005). EVA versus traditional accounting measures of performance as drivers of shareholder value : A comparative analysis. Meditari Accountancy Research, 13 (2), $1-16$.

Xin, Zhao, Ting, Wang \& Yuan, Zheng. (2012). Economic Value Added for Performance Evaluation: a Financial Engineering. Systems Engineering Procedia, 5, 379 - 387.

https://www.idx.co.id/ 